\title{
EFFECT OF AIR PERMEABILITY ON STABILITY OF SUPERSONIC PARACHUTE
}

\author{
Xue YANG $\mathbb{B}^{*}$ \\ Southwest China Institute of Electronic Technology, Chengdu, China
}

Received 30 June 2020; accepted 30 October 2020

\begin{abstract}
A compressible air permeability model is developed to simulate the aerodynamic performance of the supersonic porous canopy. And a single-degree-of-freedom model is applied to analyse the static stability of the parachute. By using this method, the flow structure of the parachute system with big attack angle is obtained. The aerodynamic moment coefficients of porous and nonporous canopies are compared to discuss the effect of air permeability on stability of the supersonic parachute. The numerical results show that aerodynamic moment coefficient of the system with air permeability has larger oscillation amplitude and value than that without air permeability. This method can be developed as a potential method to select the supersonic parachute initially.
\end{abstract}

Keywords: porous canopy, stability, supersonic flow, attack angle, parachute.

\section{Introduction}

Stability of the parachute is one of the decisive factors for the parachute working reliability. Unstable parachute is harmful to health of the parachutist and hit accuracy of the missile. The mostly used numerical method for parachute stability is the multiple-degree-of-freedom rigid body method. It simplifies the canopy, suspension lines and payload as rigid body for dynamic study. Neustadt and Ericksen (1967) simplify the parachute system as a twodimensional system. The connection between the payload and the parachute is regarded as rigid. Thus, this threedegree-of-freedom rigid body model is used to study the angular velocity and stability of the parachute. Liu et al. (2007) simulate the parachute and the payload as six-degree-of-freedom rigid body and three-degree-of-freedom rigid body, respectively. The trajectory and orientation of the rotating parachute are analyzed. Vishniak (1993) simulate the parachute and the payload both as six-degree-offreedom rigid body. The stability and swing of the parachute system are discussed by this model. Compared with Vishniak (1993), Guglieri (2012) simulates the suspension lines as six-degree-of-freedom rigid body in addition to the system. Behaviour of a parachute-payload system during the terminal descent phase is studied by this method. Multiple-degree-of-freedom rigid body method is easy to program. The aerodynamic parameter of the parachute in this method depends on the added mass model. However, the added mass model is very rough, which differs a lot from the reality. And the air permeability can't be considered in this method.

In fact, air permeability has big influence on the parachute stability. The influence law is an important foundation for material selection of the canopy. Size of air permeability reaches micron order while the parachute is generally meter scale, so aerodynamic performance of porous canopy should be simulated by special air permeability model. Sarpkaya and Lindsey (1991) correct flow field equations by artificial air permeability coefficient to study effect of the air permeability. Cheng et al. (2014) impose Ergun equations into the momentum equations to study flow features of the parachute system with porous canopy. Takizawa et al. (2017) describe pressure drop of the porous canopy by Darcy-Forchheimer model. The above-mentioned methods are all aimed at subsonic parachute and incompressible flow. And the effect of air permeability on stability of the parachute system has not been discussed.

The air permeability and stability of the subsonic parachute can be considered both by the Simple Arbitrary Lagrangian-Eulerian (SALE) method (Yu et al., 2014; Cheng et al., 2012). This method has also been used for supersonic parachute (Lingard \& Darley, 2007). The drag coefficient of the numerical results is consistent with that

*Corresponding author. E-mail: yangxuejia@nuaa.edu.cn 
of the wind tunnel test. However, there exist two problems. 1) The subsonic air permeability model can't be used for supersonic parachute system because compressible flow has different characteristic from the incompressible flow. 2) The bow shock may break nonphysically when the SALE method is used for supersonic parachute. The Fluidstructure-interaction (FSI) method has not been perfectly combined with the air permeability model for supersonic parachute so far.

In this paper, the aerodynamic calculation of the supersonic parachute with air permeability is analysed for preliminary study of the stability. Compressible Ergun equations are imposed into the aerodynamic momentum equations of the three-dimensional Navier-Stokes equations to study flow features of the parachute system with porous canopy. A single-degree-of-freedom model is used to analyse relationship of the aerodynamic moment coefficient with the static stability of the parachute system. A typical disk-gap-band parachute is modeled to check the availability of this method. The aerodynamic calculation of the parachute with big attack is achieved and it is postprocessed to obtain moment coefficient of the system. The numerical results show that this method is a potential tool to analyse the static stability of the parachute system.

\section{Mathematical model}

\subsection{Mathematical model of flow field}

The Navier-Stokes equations are used for the supersonic parachute with porous canopy,

$$
\frac{\partial(w)}{\partial t}+\nabla \cdot F(w)=\nabla \cdot R(w)+s
$$

where $w$ is the flow field parameter vector, $F$ is the convective term, $R$ is the dissipative term, $s$ is the momentum source term for the air permeability. For the subsonic parachute (Cheng et al., 2014), the incompressible Ergun equations are imposed into the momentum equations to describe pressure drop through the fabric,

$$
s_{i}=-\nabla p=\left(a v_{i}+b|v| v_{i}\right),
$$

where, $a$ and $b$ are the parameters to describe air permeability (Yang et al., 2019), $p$ is the pressure, $v$ is the velocity vector. In order to describe the supersonic parachute, the compressible Ergun equation (Moreira, 2004) is used,

$$
I_{y} \frac{\partial^{2} \alpha}{\partial t^{2}}=\sum M_{y}=M(\alpha)+M\left(\frac{\partial \alpha}{\partial t}\right),
$$

where, $I_{y} \frac{\partial^{2} \alpha}{\partial t^{2}}=\sum M_{y}=M(\alpha)+M\left(\frac{\partial \alpha}{\partial t}\right), I_{y} \frac{\partial^{2} \alpha}{\partial t^{2}}=\sum M_{y}=$ $M(\alpha)+M\left(\frac{\partial \alpha}{\partial t}\right)$ and $v_{\mathrm{q}}$ are the inlet pressure, outlet pressure and velocity of the flow through the canopy, respectively. $I_{y} \frac{\partial^{2} \alpha}{\partial t^{2}}=\sum M_{y}=M(\alpha)+M\left(\frac{\partial \alpha}{\partial t}\right)$ is the canopy thickness. $I_{y} \frac{\partial^{2} \alpha}{\partial t^{2}}=\sum M_{y}=M(\alpha)+M\left(\frac{\partial \alpha}{\partial t}\right)$ is very small, so,

$$
I_{y} \frac{\partial^{2} \alpha}{\partial t^{2}}=\sum M_{y}=M(\alpha)+M\left(\frac{\partial \alpha}{\partial t}\right) .
$$

Thus, for the supersonic parachute,

$$
I_{y} \frac{\partial^{2} \alpha}{\partial t^{2}}=\sum M_{y}=M(\alpha)+M\left(\frac{\partial \alpha}{\partial t}\right) .
$$

\subsection{Single-degree-of-freedom parachute-payload model}

In order to study the static stability of the parachutepayload system, the system in the terminal decent state is equivalent to be a single-degree-of-freedom model (Wang, 1997) under four assumptions. 1) The system is a rigid body and its lateral displacement is ignored. 2) The aerodynamic moment coefficient is zero when the attack angle is zero. 3) Disturbance is instantaneous and discontinuous. The static stability is only discussed when the disturbance is over. 4) Aerodynamic moment coefficients of the parachute and payload approximately have a linear relation with the attack angle when the attack angle is small. This model has been only used for dynamic study of the parachute before. Figure 1 illustrates the single-degreeof-freedom parachute-payload model. $o$ is the centroid of the parachute system. $M$ is aerodynamic moment at the centroid $o . \alpha$ is the attack angle. The degree of freedom of this system is the rotational freedom around $y$ axis, so the equation of motion is,

$$
I_{y} \frac{\partial^{2} \alpha}{\partial t^{2}}=\sum M_{y}=M(\alpha)+M\left(\frac{\partial \alpha}{\partial t}\right),
$$

where $I_{y}$ is the aerodynamic moment of inertia of the system around the centroid.

$$
\begin{aligned}
& M(\alpha)=\left[C_{m}(\alpha)+C_{m w}(\alpha)\right] q A_{0} D_{0} ; \\
& M\left(\frac{\partial \alpha}{\partial t}\right)=\left[C_{m}\left(\frac{\partial \alpha}{\partial t}\right)+C_{m w}\left(\frac{\partial \alpha}{\partial t}\right)\right] q A_{0} D_{0},
\end{aligned}
$$

where $C_{m}(\alpha)$ and $C_{m \mathrm{w}}(\alpha)$ are the aerodynamic moment coefficients of the parachute and payload, respectively. $C_{m}\left(\frac{\partial \alpha}{\partial t}\right)$ and $C_{m \mathrm{w}}\left(\frac{\partial \alpha}{\partial t}\right)$ are the damping moment coefficients of the parachute and payload, respectively. $A_{0}$ is the nominal area of the canopy. $D_{0}$ is the canopy diameter. $q$ is the dynamic pressure. According to the wind tunnel test results (Wang, 1997), generally, $\frac{\partial C_{m}}{\partial\left(\frac{\partial \alpha}{\partial t}\right)}>>\frac{\partial C_{m w}}{\partial\left(\frac{\partial \alpha}{\partial t}\right)}$, $\frac{\partial C_{m}}{\partial \alpha}>>\frac{\partial C_{m w}}{\partial \alpha}$. In addition, aerodynamic moment coefficients of the parachute and payload approximately have a linear relation with the attack angle when the attack angle is small. Then,

$$
M(\alpha)=\frac{\partial C_{m}}{\partial \alpha} \alpha q A_{0} D_{0} ;
$$




$$
M\left(\frac{\partial \alpha}{\partial t}\right)=\frac{\partial C_{m}}{\partial\left(\frac{\partial \alpha}{\partial t}\right)} \frac{\partial \alpha}{\partial t} q A_{0} D_{0} .
$$
then,

Substitute equation (9) and (10) into equation (6),

$$
I_{y} \frac{\partial^{2} \alpha}{\partial t^{2}}-\frac{\partial C_{m}}{\partial\left(\frac{\partial \alpha}{\partial t}\right)} \frac{\partial \alpha}{\partial t} q A_{0} D_{0}-\frac{\partial C_{m}}{\partial \alpha} \alpha q A_{0} D_{0}=0 .
$$

Equation (11) can be written in the following form,

$$
\frac{\partial^{2} \alpha}{\partial t^{2}}+2 n \frac{\partial \alpha}{\partial t}+c^{2} \alpha=0
$$

where,

$$
\begin{gathered}
n=-\frac{\frac{\partial C_{m}}{\partial\left(\frac{\partial \alpha}{\partial t}\right)} q A_{0} D_{0}}{2 I_{y}} ; \\
c^{2}=-\frac{\frac{\partial C_{m}}{\partial \alpha} q A_{0} D_{0}}{I_{y}} .
\end{gathered}
$$

When $c^{2}>0$, that is, $\frac{\partial C_{m}}{\partial \alpha}<0$, the system is statically stable. When $c^{2}>0, n>0$, the system is dynamically stable. Obviously, static stability is the premise of the dynamic stability. In this paper, only the static stability of the supersonic parachute system is studied. The dynamic stability of the supersonic parachute system would be studied in the future.

The aerodynamic moment coefficient

$$
C_{m}=\frac{M}{q A_{0} D_{0}}=\frac{-L_{1}\left(F_{x} \cos \alpha+F_{z} \sin \alpha\right.}{q A_{0} D_{0}},
$$

where $L_{1}$ is the distance between the centroid $o$ and the point of resultant point. $F_{x}$ and $F_{z}$ are the force of parachute-payload system in the $x$ and $z$ direction, respectively. The sign of the vector is consistent with that in Figure 1. According to second and fourth assumptions,

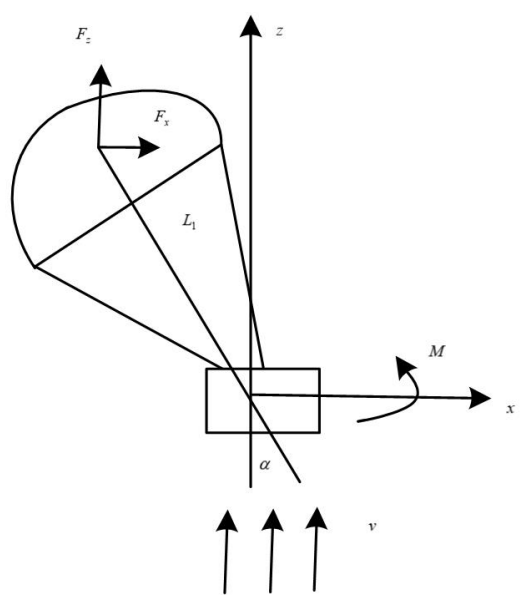

Figure 1. Single-degree-of-freedom parachute-payload model when $C_{m}$ has different sign from $\alpha, \frac{\partial C_{m}}{\partial \alpha}<0$, that is, the parachute-payload system is a statically stable system. And the higher value of $\left|C_{m}\right|$ indicates a higher stability of the parachute-payload system.

\section{Numerical model}

A disk-gap-band parachute (Sengupta et al., 2009) in the terminal decent state is simulated to study its static stability. The parameter of this model is illustrated in Figure 2. The parachute-payload systems whose attack angles are $0^{\circ}, 5^{\circ}, 10^{\circ}$ are used to investigate their static stability. The Mach number, dynamic pressure and Reynolds number of the supersonic fluid are $2,16.8 \mathrm{kPa}$ and $1.0 \times 10^{6}$, respectively. The characteristic length used to determine the Reynolds number is the nominal diameter of the canopy. It is $0.8 \mathrm{~m}$ in this paper. The grid independence of the porous parachute whose attack angle is $10^{\circ}$ is shown as an example. The grid independence of other study case works in the same way. As shown in Table 1, the average value of the drag coefficient of mesh_3 is only $4.2 \%$ smaller than that of mesh_4. Thus mesh_3 is chosen for the following simulation.

The three-dimensional flow field mesh is illustrated in Figure 3. In order to apply the air permeability model for the canopy, tri-prism grids are used. In region 1, tetrahedral grids are used for mesh around the canopy because they can be transition for tri-prism grids. In region 2, hexahedral grids are used to reduce calculation cost. The size of the grid around the canopy is $0.01 \mathrm{~m}$. The regions where the shock wave and wake locate are locally refined to simulate flow field parameters in great gradient. The average skewness of the mesh is about 0.4 . The pressurefar-field condition is applied to the flow field boundary.

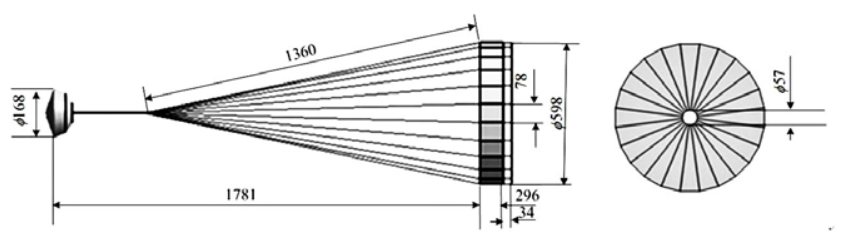

Figure 2. Parameters of a disk-gap-band parachute (mm)

Table 1. Grid independence analysis of the model

\begin{tabular}{|c|c|c|c|c|}
\hline $\begin{array}{c}\text { The } \\
\text { number } \\
\text { of the } \\
\text { grids }\end{array}$ & $\begin{array}{c}\text { The } \\
\text { number of } \\
\text { tri-prism } \\
\text { grids }\end{array}$ & $\begin{array}{c}\text { The } \\
\text { number of } \\
\text { tetrahedral } \\
\text { grids }\end{array}$ & $\begin{array}{c}\text { The } \\
\text { number of } \\
\text { hexahedral } \\
\text { grids }\end{array}$ & $\begin{array}{c}\text { Average } \\
\text { value } \\
\text { of drag } \\
\text { coefficient }\end{array}$ \\
\hline Mesh_1 & 13262 & 225683 & 167390 & 0.46 \\
\hline Mesh_2 & 19203 & 368261 & 237589 & 0.63 \\
\hline Mesh_3 & 29123 & 561372 & 357853 & 0.71 \\
\hline Mesh_4 & 42179 & 747931 & 439756 & 0.74 \\
\hline Mesh_5 & 62975 & 1028765 & 620822 & 0.73 \\
\hline
\end{tabular}




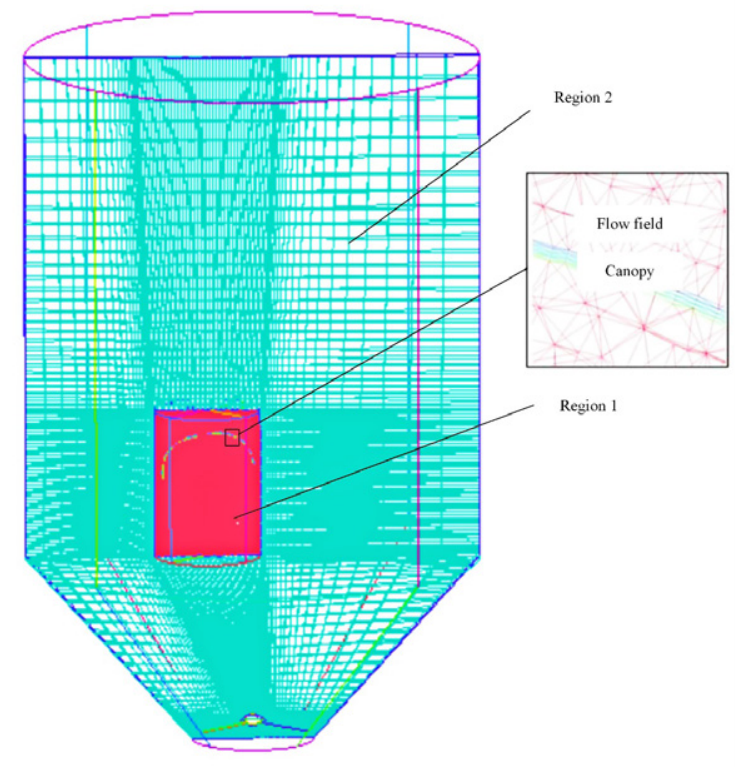

Figure 3. Flow field mesh of the parachute system whose attack angle is $10^{\circ}$

The pressure, Mach number and temperature of the pressure-far-field condition are $6000 \mathrm{~Pa}, 2$ and $375 \mathrm{~K}$, respectively. The density is calculated by the ideal gas equation. The viscosity coefficient is calculated according to Sutherland's law. The nonslip condition is applied to the payload and nonporous canopy boundary. Compressible Ergun equations are imposed into the momentum equations of the three-dimensional Navier-Stokes equations to simulate the porous canopy.

\section{Results and discussion}

Mach number contour of the supersonic parachute system in the terminal decent state with porous canopy is illustrated in Figure 4. Its attack angle is $0^{\circ}$. Two bow shocks form in front of the porous canopy and payload. The wake of the payload is interacted with the bow shock of the porous canopy, so this bow shock is approximately conical. In addition, the interation leads to strongly unsteady characteristic of the flow field in the canopy. Bow shock of the payload changes little when parameters of the flow field boundary are fixed. So in the following discussions, the flow field around the payload is not shown.

The aerodynamic moment coefficients of the porous and nonporous canopy are illustrated in Figure 5. $t$ is the time, $s$ is the unit of the time. The average value of the aerodynamic moment coefficient is approximately zero when the attack angle is zero. Average value of the aerodynamic moment coefficient of the canopy approximately has a linear relation with the attack angle. It is shown that the second and fourth assumptions of the single-degree-of-freedom parachute-payload model are correct. And when $C_{m}$ has different sign from $\alpha$, it can be concluded that the system is a statically stable. The sign of the attack angle is positive, so the system is a statically

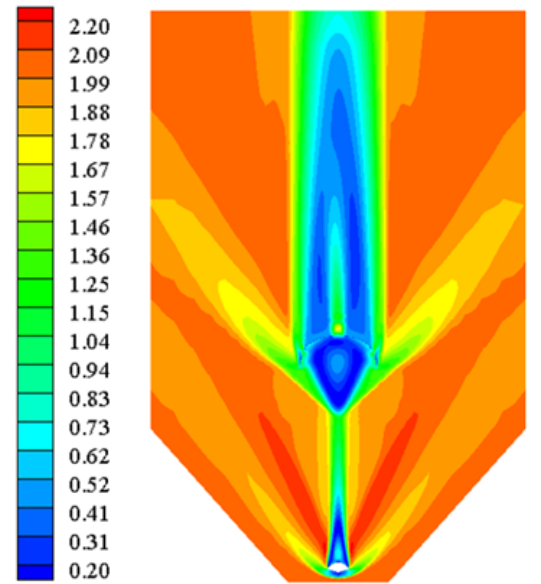

Figure 4. Mach number contour of the supersonic parachute system with porous canopy

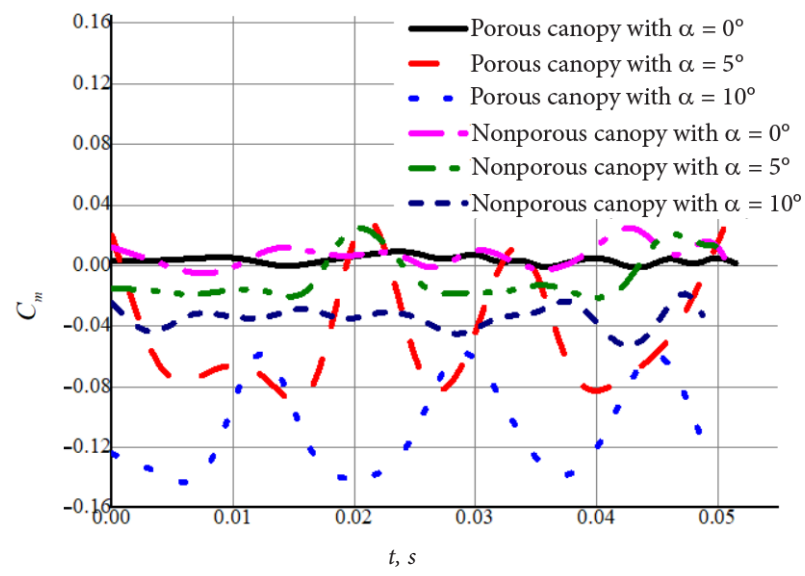

Figure 5. Aerodynamic moment coefficient

stable system when the sign of the aerodynamic moment coefficient is negative. Sign of the aerodynamic moment coefficients of the porous and nonporous canopy are both negative. So this disk-gap-band parachute has good aerodynamic shape to be statically stable. The aerodynamic moment coefficient of the canopy in absolute terms increases with the increase of the attack angle. The aerodynamic moment coefficient of the porous canopy in absolute terms is larger than that of the nonporous canopy. It indicates that the existence of the air permeability improves the stability of the system. This phenomenon is consistent with the engineering experience. The aerodynamic moment coefficient oscillates periodically due to the interaction of the wake of the payload and the bow shock of the canopy. Oscillation amplitude of porous canopy is much larger than the nonporous canopy.

Figure 6 and Figure 7 are velocity streamlines and pressure contours around the nonporous and porous canopy at five typical instants in an oscillation cycle. One side of the canopy is downward and another side of the canopy is upward when the attack angle exists. 

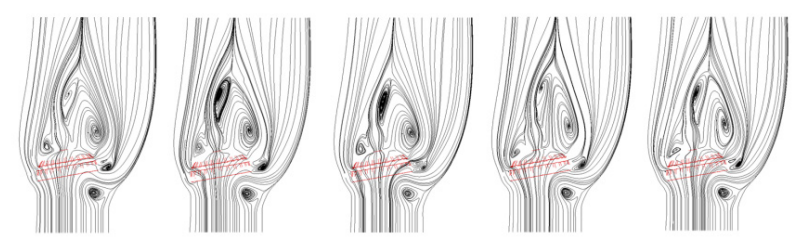

(a)
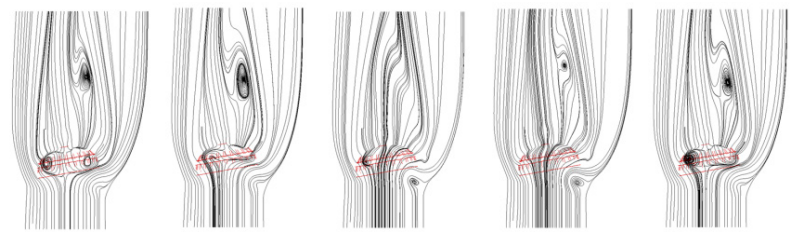

(b)

Figure 6. Velocity streamlines: a - Nonporous canopy; b Porous canopy
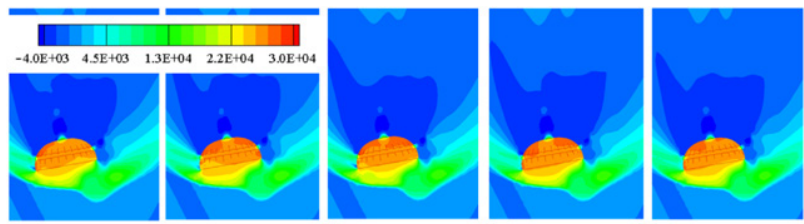

(a)
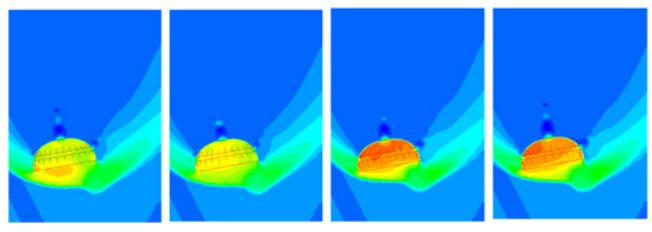

(b)

Figure 7. Pressure contour (Pa): a - Nonporous canopy; b Porous canopy

Separation point of the downward side moves backward, resulting in decrease of the flow separation. Separation point of the upward side moves forward, resulting in increase of the flow separation. The imbalance lateral force produces restoring aerodynamic moment at the canopy. Then the parachute system is statically stable. There is no vortex in the canopy without air permeability, thus its flow field is steadier. As for the porous canopy, there is a pair of unsteady vortices inside, so oscillation amplitude of this system is much larger. And it also leads to larger restoring aerodynamic moment of this system. Obviously, there are streamlines penetrating the fabric, which shows that the air permeability model can model the air permeability successfully. And the existence of the air permeability makes the wake of the porous canopy narrower and further back than the nonporous canopy. It also makes the porous canopy has longer standoff distance and lager oscillation amplitude.

\section{Conclusions}

The mathematical model of flow field for the supersonic parachute with porous canopy is constructed. A singledegree-of-freedom parachute-payload model is applied to analyse static stability of the parachute system for the first time. The flow field of the supersonic parachute system with attack angle are obtained to analyse the effect of the air permeability on its stability. The conclusions are as follows:

1. A compressible air permeability model is used for the supersonic porous canopy. And the canopy zone is discretized using tri-prism grids. The numerical results show that this method can successfully simulates the streamlines penetrating the fabric.

2. When the aerodynamic moment coefficient has different sign from the attack angle, the system is statically stable. And the lager average value of the aerodynamic moment coefficient indicates a more stable system. The disk-gap-band parachute used in this paper is statically stable.

3. The numerical results of the porous canopy and nonporous canopy are compared. Oscillation amplitude and average value of aerodynamic moment coefficients of the porous canopy are larger than that of nonporous canopy. It shows that system with porous canopy is more statically stable. And the existence of the air permeability results in smaller and further back wake of the canopy.

The above-mentioned method can reveal a lot of information about the flow field of the supersonic parachute system with porous canopy. It is also an effective tool to screen out the unstable parachute system. Furthermore, cases with big angle of attack can be taken into consideration for the future work. The dynamic stability of the parachute system with porous canopy can also be studied in the future.

\section{Acknowledgements}

This work was co-supported by National Nature Sciences Foundation of China (Nos 11972192, 11172137).

\section{References}

Cheng, H., Yu, L., \& Rong, W. (2012). A numerical study of parachute inflation based on a mixed method. Aviation, 16(4), 115-123. https://doi.org/10.3846/16487788.2012.753676

Cheng, H., Yu, L., \& Chen, X. (2014). Numerical study of flow around parachute based on macro-scale fabric air permeability as momentum source term. Industria Textile, 65(5), 271-276.

Guglieri, G. (2012). Parachute-Payload System flight dynamics and trajectory simulation. International Journal of Aerospace Engineering, 2012, 182907, 1-17. https://doi.org/10.1155/2012/182907

Lingard, J. S., Darley, M. G., \& Underwood, J. C. (2007, 21-24 May). Simulation of the Mars science laboratory parachute performance and dynamics. In $19^{\text {th }}$ AIAA Aerodynamic Decelerator 
Systems Technology Conference and Seminar. Williamsburg, VA. AIAA 2007-2507. https://doi.org/10.2514/6.2007-2507

Liu, W., Tang, Q., \& Kou, B. H. (2007). Numerical simulation of velocity and spin speed of parachute-spinning projectile system. Acta Armament Arii, 28(11), 1302-1305.

Moreira, E. A. (2004). Air permeability of ceramic foams to compressible and incompressible flow. Journal of the European Ceramic Society, 24(10), 3209-3218.

https://doi.org/10.1016/j.jeurceramsoc.2003.11.014

Neustadt, M., \& Ericksen, R. (1967). A parachute recovery system dynamic analysis. Journal of Spacecraft \& Rockets, 4(3), 321-326. https://doi.org/10.2514/3.28860

Sarpkaya, T., \& Lindsey, P. J. (1991). Unsteady flow about porous cambered shells. Journal of Aircraft, 28(8), 502-508. https://doi.org/10.2514/3.46055

Sengupta, A., Wernet, M., \& Roeder, J. (2009, 4-7 May). Supersonic Testing of $0.8 \mathrm{~m}$ disk gap band parachutes in the wake of a $70 \mathrm{deg}$ sphere cone entry vehicle. In 20th AIAA Aerodynamic Decelerator Systems Technology Conference and Seminar (pp. 1-16). Seattle, Washington. AIAA. https://doi.org/10.2514/6.2009-2974
Takizawa, K., Tezduyar, T. E., \& Kanai, T. (2017). Porosity models and computational methods for compressible-flow aerodynamics of parachutes with geometric porosity. Mathematical Models \& Methods in Applied Sciences, 27(4), 771-806. https://doi.org/10.1142/S0218202517500166

Vishniak, A. (1993). Simulation of the payload-parachute-wing system flight dynamics. In AIAA 1993-1250 (pp. 1-7). https://doi.org/10.2514/6.1993-1250

Wang, L. R. (1997). Parachute theory and applications (pp. 236241). Aerospace Press.

Yang, X., Yu, L., \& Nie, S. C. (2019). Aerodynamic performance of the supersonic parachute with air permeability. Journal of Industrial Textiles, 50(6). https://doi.org/10.1177/1528083719844605

Yu, L., Cheng, H. \& Zhan, Y. N. (2014). Study of parachute inflation process using fluid-structure interaction method. Chinese Journal of Aeronautics, 27(2), 272-279. https://doi.org/10.1016/j.cja.2014.02.021 